\title{
An Investigation on the Widespread Use of Zero Hours Contracts in the UK and the Impact on Workers
}

\author{
Ernestine Gheyoh Ndzi \\ York Business School, York St John University, York, United Kingdom
}

Email address:

e.gheyohndzi@yorksj.ac.uk

\section{To cite this article:}

Ernestine Gheyoh Ndzi. An Investigation on the Widespread Use of Zero Hours Contracts in the UK and the Impact on Workers. International Journal of Law and Society. Vol. 4, No. 2, 2021, pp. 140-149. doi: 10.11648/j.ijls.20210402.21

Received: February 8, 2021; Accepted: February 18, 2021; Published: June 15, 2021

\begin{abstract}
The use of zero hours contract (ZHC) amongst employers in the UK continue to grow with little or no job security. There has been growing concern on how this type of employment contract is affecting workers socially, economically, health and otherwise. Existing research on ZHC focuses on low paid jobs, hence the importance of this study. The aim of this paper is to investigate how ZHC affect the worker with a focus on establishing the difference in experience between workers from across different sectors. Data for the study is obtained from conducting thirty-six semi-structured interviews with people working on ZHC. Participants for the study worked in health, education, hospitality, security, construction, and retail sectors, to understand if worker's experience might differ based on the sector in which they work. The result demonstrated that the use of ZHC contract has spread to sectors such as education (lecturing jobs) which are generally considered as high skilled jobs as opposed to prevalence of ZHC in low skilled jobs as documented by previous research. Flexibility remained the key element of ZHC that all the workers enjoyed and would like to retain. However, the uncertainty and insecurity of the contract affects workers financial stability, social and family life, job quality and satisfaction; career progression and health. The negative impact of ZHC is largely the same with workers in lecturing job driven by insecurity and uncertainty. Although workers in the education sector (teaching staff) reported knowing their schedule for a semester or academic year, issues such as the lack of opportunities for career progression, no/limited training provided where required, stress and anxiety relating to the insecurity and uncertainties remain a growing concern. The use of ZHC contract in sectors such as education (lecturing jobs) which are generally considered as high skilled jobs is concerning and demonstrate how precarious the United Kingdom's labour market is increasing becoming insecure.
\end{abstract}

Keywords: Zero Hours Contract, Education, Employment Right, Worker's Health, Health and Career Wellbeing, Employer Support

\section{Introduction}

The rise in the use of precarious contracts - contracts with little or no security, characterised by low levels of pay and fluctuating working hours - and its effect on the workers' wellbeing [28] remains a contentious issue in the UK. Zero hours contract (hereafter referred to as ZHC) is part of the "atypical" work arrangements that exist in the UK. ZHC had been considered by a UK House of Commons research note as a "colloquial term for an employment contract under which the worker is not guaranteed work and is only paid for work carried out" However, others have included workers being available for work and 'on call' as an important requirement of a ZHC [38]. ZHC contract in essence, mean that a worker is promised work if and only when the employer chooses to provide it. Therefore, there is no guarantee as to when work may become available for the worker leading to job instability [24]. The rationale for ZHC is that it offers the employer flexibility to recruit more staff when needed and for the worker to only work when they are able to and not be tied to any contract. ZHC is expected to improve employment and labour participation through its market flexibility [8]. Supporters of ZHC have relied heavily on this flexibility to justify the need for this type of employment relationships [37]. For example, workers with parental/caring responsibilities could use the flexibility to balance work and family life and students could use the flexibility to balance work and studies (Pyper and Powell 
2018). The flexibility allows full time employees to transition to retirement and plays a vital role as a stepping-stone unto more stable jobs for some people [19]. However, research studies have demonstrated that the insecurity that comes with working on ZHC can have negative consequences on the worker such as financial difficulties [23], strain on family relationship [41], and social relationships [33], poor physical [14] and mental health, [8] and increased stress [13]. Farina et. al. [21] points out that ZHC workers have on average fewer training opportunities, poorly paid and concentrated in particular occupation and industries. Sanwald and Theurl [46] investigating the impact of contracts such as temporary, on call, daily or no formal contract and health outcomes such as occupational injuries, health related behaviour, mental health and physical health, concluded that there was a higher risk of occupational injuries for people working on atypical contracts and an increase likelihood of mental and physical health. Henderson [25] reported higher levels of poor mental health among 25 year-olds working on ZHCs than among 25 year-olds in other forms of employment after controlling for observable worker characteristics. Pyper and McGuinness [39] writing on job satisfaction found that workers were happy with the flexibility that ZHC offers. Farina et al [21] points out that workers on precarious work have a higher risk of work-related injuries and illness because of little training on occupational health, safety procedures, and less familiarity with the work practice and environment. Burchell [12] argued that job insecurity is damaging to psychological health and worker motivation. ZHCs pay significantly lower wage rates, approximately one-third lower than the average hourly wage among non-ZHC workers [30]. Ravalier et al [40] pointed out that ZHC has adverse effect on worker's job motivation [22], stress and influences worker's well-being. Ball et al [7] considered the extent to which agency workers and zero hours contracts were used in the UK and worker's vulnerability as a result of the Sports Direct zero-hour contract worker's abuse scandal. The scandal flagged the poor treatment of workers on zero-hours contracts who were subjected to bullying and harassment which left workers feeling vulnerable, and unable to plan their lives or budget effectively [35]. It has been argued that temporary jobs, which include $\mathrm{ZHC}$, does not lend itself to career pathways because they are associated with low levels of job satisfaction and poor work-related training [9, 19]. Existing literature have considered $\mathrm{ZHC}$ as part of the temporary work and data collected were from fixed term low paid work, part time work, casual work, agency work, etc. This study considers only people identified to be working on ZHC within the definition of Section 27A of the Employments Rights Act (ERA) 1996. It covers experience from people working in different sectors as opposed to one sector to consider whether the experience is the same or different across sectors. Furthermore, existing literature rely heavily on the experience of workers in low paid jobs such as health care work, security, etc.

The aim of this study is to determine how the use of $\mathrm{ZHC}$ has spread to other sectors such as education which is an area of public sector that is traditionally unionised and where most employers reluctantly accept the presence of collective bargaining. The study includes comparing experiences in lecturing roles in universities to the experience of workers in other sectors. This study adds to the body of knowledge on ZHC studies but provides new findings on worker's experience across different sectors and demonstrating the spread in use of ZHC. The paper is divided into three sections. The first section will examine the growth of $\mathrm{ZHC}$ in the UK. The second section will discuss the legal position of $\mathrm{ZHC}$ and the unintended consequences and the final section will cover the methodology, research findings/discussion.

\subsection{The Growth of ZHC in the UK}

The UK has witnessed a significant increase in the use of ZHC from 225,000 workers in 2000 to 974,000 workers in 2019 [32]. Kalleberg and Vallas [28] attributed the increase in the use of ZHC to the political landscape that increased the power of capitalism at the expense of labour. Research demonstrates that some workers do not know the type of contract they are employed on. This suggest that the number of people on ZHC could be higher than what is currently being disclosed on the ONS data. According to the ONS, the number of people on ZHC represents $3 \%$ of UK workforce. ZHC was/is welcomed by most people because of the flexibility it offers although, Reilly [42] argues that 'flexibility has become a politicised word - a term of abuse or approbation'. Elliott [20] argued that ZHCs provides a precarious labour reserve that is temporary, low waged, low skilled and low opportunity.

The UK government views $\mathrm{ZHC}$ as an alternative to unemployment and as a pathway to other forms of employment attracted by the ability to create jobs and reduce unemployment [42]. ZHC is more common but not exclusive to young people. Use of $\mathrm{ZHC}$ is common in sectors and occupation where variation in service/product demand can have an immediate effect on labour demand [15]. In such sectors, employers may use ZHC to adjust working times as necessary which is common in retail sector [44] and the health sector [17]. Supporters of ZHC described it as a vital tool for economic recovery and necessary to lower unemployment while allowing employers to adapt swiftly to changing demand [26]. ZHC has been argued to have a place in the labour market offering opportunities to especially students and single mothers who would otherwise find it difficult to take on regular work with fixed hours [27]. In the UK increasing proportions of students and women are working on ZHC. This type of contracts uses age and gender to control labour whilst minimising costs and maximising flexibility [31]. The use of ZHC is spreading further into sectors such as education and transport that were traditionally sectors with more secured work [47]. Use of ZHC has been reported in some big companies such as Tesco, McDonalds, Amazon, Sports Direct, etc. [47] on jobs described as low skilled. ONS (2018) statistics demonstrated that 28\% of employers using ZHC were big companies employing at least 250 employees and only 5\% of employers with less than 10 
employees. Pickavance [34] studying people working on ZHC in 2014, found out that a third (a third of 600,000) of the workers had $\mathrm{ZHC}$ contracts because they could not find jobs with regular fixed hours. This could suggest that employers are increasing using ZHC rather than employing on permanent contract making the labour market very precarious [43]. However, the spread of ZHC to sectors such as education can be concerning.

\subsection{The Legal Position and Unintended Consequence of a $\mathrm{ZHC}$}

The legal status of every working person is crucial in law as it determines what statutory rights and obligations an individual has in respect to their work and employer. In the UK an individual could be regarded as an 'employee' or a 'worker'. Section 27A of the Employments Rights Act (ERA) 1996 defines ZHC as a contract of employment or other worker's contract under which (a) the undertaking to do or perform work or services is an undertaking to do so conditionally on the employer making work or service available to the worker, and (b) there is no certainty that any such work or services will be made available to the worker. People on ZHC are generally classed as workers defined under s230 (3) ERA 1996. This mean that workers on ZHC have access to limited sets of employment rights (Brown et. al. 2000). Their employment rights would include right to discrimination protection, National Minimum Wage and paid annual leave; but these rights are not extended to right to unfair dismissal, etc. All employment rights are only available to people regarded as employees according to s230 of the ERA 1996 and Hall v Lorimer [1993] EWCA Civ 25. The key difference between the worker and the employee being the lack of mutuality of obligation [16]. Mutuality of obligation meaning the lack of obligation for the employer to provide the worker with work and the lack of obligation for the worker to do the work the employer may offer. While an employee is guaranteed work and is under an obligation to do the work the employer has provided, a worker on zero hours contract is not guaranteed work and is not expected to do the work the employer may offer.

The lack of mutuality of obligation in ZHC mean the worker cannot be classified as an employee and are therefore excluded from some key employee benefits and protection provided by the law. For example, workers in the UK have a right to be paid the national minimum (or living) wage for periods of work, no matter how short the period of work was. In calculating the correct rate of pay, the National Minimum Wage (NMW) Regulations 1998 (as amended) differentiates pay arrangements as 'salaried hours work', 'time work', 'unmeasured work' and 'output work'. ZHC workers are classed as 'time work' because they are paid hourly depending on work they have done (Section 3 National Minimum Wage Regulations 1999). The regulation does not class time spent travelling to work as 'work' but time spent travelling between locations for work purposes comes within the scope of NMW and should be paid. This is an important issue to consider because most ZHC workers don't get paid for time spent travelling between locations for work. Time spent travelling between work is particularly important in the health sector where zero hours workers are often not paid for travel time between clients or 'on-call' hours. The National Audit Office estimated that as many as 160,000 to 220,000 care workers in England were paid below the NMW because of this (National Audit Office 2014).

Despite the flexibility that ZHCs accords the employer and the worker, there has been growing concerns about the negative impact that it may have on worker's welfare [45]. ZHC has come under political, media and academic scrutiny [2]. Despite the positive reasons advanced for the existence of $\mathrm{ZHC}$, research demonstrates that it hinders workers from progressing through the ranks of an organisation [34] and harm earnings [5]. Employers have the right to hire and fire at will with no fear of going against the law [11]. Workers on ZHC cannot rely on employment law and are excluded from employee benefits [1]. Zero hours contract scandals by companies such as Sports Direct and Amazon [10] demonstrates employers' discretion to avoid key obligations owed to workers, while the worker is expecting flexibility, good working conditions and a minimum regularity of working time to enable them meet their basic needs. The imbalance in bargaining powers gives employers the opportunity to impose expectations on ZHC workers. Although, a worker may be able to challenge these terms of contract in court [4], many often are less likely to pursue claims in court. In the case of Nethermere (St Neots) v Gardiner [1984] IRLR 240, Lord Justice Stephenson held that a well-founded expectation of continuing homework should be hardened or refined into an enforceable contract because there was a regular giving and taking of work over a period of a year or more. Under such circumstances he said that workers should become employees under contracts of service. It has been argued that ZHC flexibility transfers business risk from the employer to the worker. Adams and Deakin [3] argued that employers recruiting on ZHC have tax and national insurance advantages on such terms. Employers have been accused of using ZHC to their advantage even if the worker suffers as a consequence as was seen in the case of Autoclenz Ltd v Belcher [2011] UKSC 41 where the courts held that the workers contracts were specifically written to deny the workers of employment rights. The courts held that the workers were in fact employees irrespective of what the contract stipulated. The decision of this case was followed in the case of Borrer v Cardinal Security Ltd [2013] UKEAT 0416_12_1607 (16 July 213) at [15].

\section{Methodology}

This research adopted a qualitative method and involved semi-structured interviews with people in the United Kingdom who were contracted to zero-hours of work. This method was appropriate because the aspects under investigation could not be studied in any other form than participants experiences. The method allows participants to provide in-depth personal experience on the subject. An 
initial online survey was conducted to collect data on intersectionality on demographics, educational level, economics status, etc. Through this survey, participants were given the opportunity to take part in an interview if they wanted. The survey received 460 responses (findings not reported in this article) and 98 people volunteered to be interviewed. All 98 participants were contacted with consent forms and information sheets for the interview. Fifty-two responded to the interview invites, but 18 pulled out before the interviews started leaving 34 voluntary participants. Two of the interviewed participants were recruited via snowballing method. A total of thirty-six semi structured interviews were conducted with each lasting on average 50 minutes. The interview sample is from six sectors (education, hospitality, health, security, retail and construction), job role, demographics and locations.

Table 1. Participant demographics.

\begin{tabular}{|c|c|c|c|c|}
\hline Respondent & Gender & Age & Finishing full time education & Sector of work \\
\hline 1 & Female & $36-45$ & I am doing or have finished a postgraduate degree & Education \\
\hline 2 & Female & $46-55$ & I have completed my undergraduate degree & Education \\
\hline 3 & Male & over 56 & I am doing or have finished a postgraduate degree & Education \\
\hline 4 & Male & $36-45$ & I am doing or have finished a postgraduate degree & Education \\
\hline 5 & Female & $18-25$ & I am a student currently doing a degree & Hospitality \\
\hline 6 & Female & $26-35$ & I am doing or have finished a postgraduate degree & Education \\
\hline 7 & Male & $36-45$ & I finished my full-time education at 16 & Care \\
\hline 8 & Female & $26-35$ & I finished my full-time education at 16 & Care \\
\hline 10 & Male & $36-45$ & I am doing or have finished a postgraduate degree & Education \\
\hline 11 & Male & $36-45$ & I finished my full-time education at 16 & Security \\
\hline 12 & Male & $18-25$ & I am a student currently doing a degree & Hospitality \\
\hline 13 & Female & $46-55$ & I finished my full-time education at 16 & Education \\
\hline 14 & Male & $46-55$ & I finished my full-time education at 16 & Health distribution \\
\hline 15 & Female & over 56 & I finished my full-time education at 16 & Care \\
\hline 16 & Female & $26-35$ & I have completed my undergraduate degree & Cinema \\
\hline 17 & Female & $46-55$ & I have completed my undergraduate degree & Education \\
\hline 18 & Male & over 56 & I have completed my undergraduate degree & Education \\
\hline 19 & Female & $26-35$ & I am doing or have finished a postgraduate degree & Education \\
\hline 20 & Female & over 56 & I finished my full-time education at 16 & Care \\
\hline 21 & Male & $18-25$ & I finished my full-time education at 18 & Hospitality \\
\hline 22 & Male & $36-45$ & I finished my full-time education at 16 & Security \\
\hline 23 & Male & over 56 & I finished my full-time education at 18 & NHS \\
\hline 24 & Female & $46-55$ & I finished my full-time education at 16 & retail \\
\hline 25 & Female & $18-25$ & I have completed my undergraduate degree & Education \\
\hline 26 & Female & $26-35$ & I have completed my undergraduate degree & Education \\
\hline 27 & Female & over 56 & I am doing or have finished a postgraduate degree & Mental health \\
\hline 28 & Female & $26-35$ & I am doing or have finished a postgraduate degree & Arts \\
\hline 29 & Female & $46-55$ & I finished my full-time education at 16 & Hospitality \\
\hline 30 & Male & $46-55$ & I am a student currently doing a degree & Transport \\
\hline 31 & Female & $26-35$ & I am doing or have finished a postgraduate degree & Care \\
\hline 32 & Male & $26-35$ & I finished my full-time education at 16 & Construction \\
\hline 33 & Male & $18-25$ & I finished my full-time education at 16 & Construction \\
\hline 34 & Male & $18-25$ & I am a student currently doing a degree & Hospitality \\
\hline 35 & Male & $36-45$ & I am doing or have finished a postgraduate degree & Housing. \\
\hline 36 & Male & $26-35$ & I have completed my undergraduate degree & Retail \\
\hline
\end{tabular}

The interviews took place face-to-face (except for four that were conducted by phone). A semi-structured interview format was followed, broadly covering flexibility and insecurity; health and wellbeing; and career wellbeing. Interviews took on average 55 minutes, which were recorded and subsequently transcribed. Ethics approval was authorised from the University and all interviewees gave their consent to the process. A manual thematic content analysis was undertaken. Coding of the themes were closely related to the aim of the study. The researcher used the first ten transcripts to familiarise herself with the data, generating initial codes and developing emerging themes. The themes were studied and reviewed to ensure that hidden themes and alternatives interpretations were accounted for. The codes were confirmed and applied to the rest of the interview analysis. This approached enriched the analysis for the research.

\section{Findings}

Thirty-six interviews were conducted with people who were working on $\mathrm{ZHC}$ at the time of the interviews. None of the participants dropped out of the study and none withdrew the information they provided either in part or whole. The participants were males and females of age 18 and above and mainly from the following sectors: hospitality, cleaning, security, driving, health and care work, and education. This provided a good mix of characteristics to provide a robust analysis. Some of the participants (6 out of 36) had positive accounts on their experience of working on ZHC. They recounted positive experience of $\mathrm{ZHC}$, how its flexibility worked for them, and more importantly where they felt or appeared to have power to determine when they wanted to 
work and to some extent, a say over the nature of that work. These were generally people who did not rely on the money as their sole income or people who were doing the work for extra money ('beer money'). Most of these people were over 56 and did not have direct financial dependents, or had a relatively advantageous domestic, economic context for example, were retired with a good pension, or people who had paid off their mortgage or people whose kids left home. For these people, the research focused less on but will used to explain what the ideal position should be for workers on ZHC.

A further 10/36 had quite an even mix of positive as well as negative elements, with the majority (20/36) presenting a largely negative picture, although even these often do show partial positive elements. This mixed picture does need to be acknowledged because it is demonstrating that where $\mathrm{ZHC}$ is used properly by the employers, it does achieve the aim for which it was created. The findings presented here focuses on this majority of our interviewees (30) who depended on the earnings from these contracts as their sole means of income for survival, for 'putting food on the table'. It is interesting that this did not only relate to low paid jobs such as health and care work, security, etc. it also included seasonal/visiting lecturing work which is better paid but the insecurity is about renewal of contract rather than daily/weekly uncertainties.

\subsection{Flexibility and Insecurity}

Even with many negative impact stories, there are also advantages to flexibility for the individual, to work around other circumstances, home life, etc. as explained by participant 9:

'In terms of childcare, it's alright, because it's flexible, as a parent.... I just pick up shifts that suit me, you know, like my circumstances, my situation at hand. I just tell them I can't work, and it goes like that, because you have choice' (9).

Some respondents compare ZHCs favourably saying it gives greater flexibility to the worker than a permanent contract, others felt the opposite, that those on ZHCs get little choice of hours and have to work more intensively in those hours i.e. without pay for meetings, training, etc. than their permanent counterparts get. A minority (6/36) felt they could submit requests, and get them approved, to take time off in future dates by giving notice. The flexibility of ZHC works for these participants as they do have some control.

For some of the workers, the flexibility comes at a cost characterised by the lack of guaranteed hours and income. The respondents described how uncertain they were about when they would work as availability ranges from year-byyear, termly (in education), to weekly rotas/shifts, to 24 hours' notice or less. Hours worked could vary widely.

'Sometimes it's a matter of hours, sometimes it's a matter of minutes. Last week it was about 7.30 that I had a phone call to go down and cover a shift that starts at 8 o'clock, then you just have approximately 30 minutes to prepare and report for work. Sometimes when they will tell you two weeks, even three weeks, you can even get a shift, so you can plan your life, but in most cases (when it quite busy) everywhere is quite heavy (and) you can be called even when the shift is starting to cover the shift' (18).

The impact of uncertainty as to when work might become available is less felt (time wise) because in the education sector activities such as exam invigilation and lecturing roles are determined either per semester or annually. Hours are therefore pretty much regular and guaranteed within that contract. The insecurity comes more with the uncertainty over contract renewal and longer-term career prospects for workers on $\mathrm{ZHC}$ in the education sector. This is contrary to the experience of workers in other sectors as their can be offered work or cancel their work within a very short space of time. Respondents explained that they could be asked to return home without pay if work did not materialise or could not be provided for some external reason.

'So if you're a zero hour, they would ask you come in and start your shift at five for all the busy evening shifts (but if they) aren't busy, on a zero hour contract they can just tell you to go home, or rather they ask you to go home. If you couldn't find anything to do to keep busy, they would expect you to leave and sign out early' (4).

However, hours and income can be stable, regular, when averaged out over weeks and months, but for an individual, weekly fluctuations can vary widely ('from 50 hours one week to 8 hours another').

'It's a challenge. There are weeks I could do 30, 40, 50 hours, but there are other weeks, like this week, for instance, I've only done 8,8 and a half hours. So, round Wednesday, Thursday I will know what I'm working next week.... So, the disadvantage is I can't plan anything out' (20).

Respondents explained that because of this insecurity they tend to - where possible - work many hours, sometimes multiple contracts, to compensate for low hourly pay and as contingency for when one contract does not materialise. This potentially leads to increase workload and contracts for some of the workers. On the other hand, some workers see the flexibility of $\mathrm{ZHC}$ as an opportunity to work more hours, hold multiple contracts, and earn more money than permanent staff.

Some of the respondents reported a lack of control as to whether they wanted to do an overtime.

'There were weeks when I did 45, sometimes 50 hours, and I did tick the box saying I didn't want to do 40-hour weeks, but just circumstances always came up' (4).

Some of the participants felt they were pressured into agreeing to work overtime at the point of recruitment. The fear of not getting the job, made them sign the contract.

'They get you to sign off that you're happy to do longer than 48 hours. Normally you get that at the first interview. You've got to sign that, otherwise you don't go any further' (6).

\subsection{Social and Family Life}

Respondents described the impact $\mathrm{ZHC}$ had on their social life. This is mainly because they were unable to predict and plan when they could go to work. Consequently, they tend to accept all or most of the work when offered as a strategy to save up for when they are not offered work. This meant that 
for those respondents, they would cancel any social engagement they may have schedule to go to work when work becomes available.

'I haven't got a social life. I just loose contact because sometimes I'm doing 60-70 hours a week. They get fed up with trying to contact you, because your answer is always the same. "No, I'm working". "Sorry, I'm working". So, it just goes' (6).

This impact does not end at the level of socialisation, but for those that had families the effect was much more about them feeling unable to provide or be there for their families.

'Sometimes I run into problems with my wife because I have no money for the family...... When you've got kids going to school, you've got people who have to eat, you've got bills, you've got to buy clothes for them' (18).

Respondents reported that the insecurity of ZHC made it difficult for them to access loans, mortgages, and pension. Workers find it difficult to sign up to the Department of Work and Pension because of the difficulty in reporting hours and income because of the constant fluctuation in hours worked.

'They say to me, "we can't give you a mortgage because you're on a zero hours contract" .... because they have to know that there is a guarantee that you will pay your mortgage. They pay you weekly, not monthly, so when you go to the bank, they have to check how much you're earning and when they see they you're working but they're paying you weekly, you're in and out of income, they won't give you because they know there's no guarantee of work with your job' (9).

\subsection{Health}

A majority of the respondents reported that their health and wellbeing had been affected because of ZHC. Health and wellbeing aspects were all related to the insecurity and uncertainty of the contract. Although, the researcher could not clinically confirm some of the conditions the workers talked about, their choice of word suggested that it effected their wellbeing.

The flexibility offered by ZHC did not quite work for the rest of the 30 respondents as it did for the 6 mentioned above. For some, it was the fear of losing work or not knowing when they will be called up to work which caused some of the respondents to go to work even when they were ill. It is to be noted here that the work was not necessarily causing the workers to be ill, but when ill and did not take time off to go to the doctors and recuperate, which made their health conditions to worsen.

'I worked through a really bad infection, where I was shaking like I had Parkinson's but couldn't afford to stay at home because the only thing I've got is statutory sick pay, which is less than I earn in a day here. I've worked through...because I just need the money so much. You know, in this day and age, when you've got three kids you've got to earn' (5)

Some of the respondents reported that the uncertainty of the contract caused them anxiety. Respondents describe that they would get anxious about when they will get work, and how much their pay will be or when their will next be given work. Often, they talk about stress, anxiety or depression, although it is difficult to confirm their health status.

Sometimes I'm depressed because it can take maybe three weeks for me to get a shift. Sometimes they'll give you three shifts in a row, then cancel it. So, it's like you get so disappointed. You start thinking "How am I going to feed my kids next week?" (9).

\subsection{Career}

For some workers, being on a ZHC led to lack of goodwill, not going beyond basic contract responsibilities and a loss of organisational commitment. Some of the respondents expressed how much they wanted to do a good job at work but were unable to because they felt they were unsupported and not valued by their employer. They said they were excluded from management/organisation decision-making, were unable to make suggestions for improvement and unable to feedback about their work because there were not given the opportunity to do so. Managers showed no interest in their career prospects and often it was not known to the workers who their manager were; and for those that knew who their managers were had limited direct contact with them.

'It makes me feel devalued, and it makes me feel quite cross. I come away from work feeling angry sometimes and I feel quite frustrated about my job. I used to come home feeling like I meant something to somebody ...I was part of making it work and making it better. I felt respected as well. Now I come home often feeling resentful and angry about the job that I have and the status that I have' (17).

On the other hand, workers in lecturing positions reported that the work they were doing was in line with their career path as opposed to others who work in different sectors just to earn a living. However, they felt they were left out of important meetings and information that could enable them to progress. One respondent reported that although, he was not being paid for attending meetings, he attended to keep up to speed with what is happening in the organisation and to demonstrate that he is a reliable staff worthy of a permanent position. Some of the respondent explained that they had to work extra hours unpaid to prove their worth to the employer with the hope that it could earn them a permanent position.

'I have to attend, so I know what they're talking about, which I'm not paid for because, I'm with a view of going permanent, I need to be involved, because I want to show I have an interest, that I'm not just doing what I'm paid for' (8).

As a result of the lack of interest in the worker's career prospects ZHC contracts constraints some workers who possessed more skill and experience from using or developing further. 18 out of the 36 workers that were interviewed were degree holders and they explained that they had no career prospect because they were not given any role of responsibility or provided with any opportunity to progress.

'I've tried to get into permanent work, but because of not 
much experience commensurate to my qualification, I can't easily get into the job market, per se' (18).

\subsection{Training}

Some of the workers were given minimal or no training necessary to the work they were doing or expected to do. Depending on the nature and type of work lack of adequate training could have implications on the quality of work done, health and safety and career development. Some of the workers were provided with the training but at a cost to be shouldered by the worker, which caused some of the workers to refuse completing the training on the basis of financial cost. Lack of training could restrict the kind of work workers could do in future by limiting their choices or narrowing the range of work they could engage with. However, workers lecturing on $\mathrm{ZHC}$ reported having adequate training.

'They do training. I don't do it, I've refused now because they won't pay me to go there. So because I kicked up such a fuss, I said "look, I'll do the training online. First aid, I can get first aid for free online, I can't afford to pay for the training". But I'm not going to give up 4 hours for them....' (10).

Furthermore, where the lack of training impacted on the worker's performance, the employer stops providing more work. ZHC could be described as a double-edged sword against the worker. Wood (2016) described the prevalent use of $\mathrm{ZHC}$ as a threat to job quality. It is apparent from this research that quality of job could be affected where workers are not provided with the required training or listened to. However, participants who were on ZHC because they could not find permanent jobs, expressed the desire for $\mathrm{ZHC}$ to be banned. Those that were on ZHC because of childcare responsibilities, or just needed extra money, did not want ZHC banned, but asked for some form of certainty and more understanding from the employers.

Other elements that were identified from the data included fear, bullying, racism and discrimination. There is a need for these elements to be investigated further because it was not sufficiently covered in this study. Workers reported being afraid or under pressure not to complain when work is withdrawn at short notice, and pressure to take on work when it is offered at short notice - for fear of work not being offered again. There is also the question of whether workers do feel/are bullied to do work or accept work as seen in the quote below.

'Once I was travelling to France for my birthday, I was on my way to the airport and I had a call, and I said "look, it's my birthday, I'm going to Paris, I'm travelling with my wife". He said "you have to come now. If you don't come I'm not going to call you again". There's a threat attached to it. Of course, I didn't go and I didn't get a call from them for a long time' (1).

Workers had an implicit fear of being punished by the employer when work was withdrawn. The respondents explained that the fear of speaking up meant that the other workers or employer could say or do whatever they want to them sometimes. Others felt they had to go above and beyond in what they do to avoid negative behaviour or comment from the employer or permanent staff.

'Yeah, there were times when they will say to me "if you don't like it you can just go get another job. You're on a zero hour contract, you're not obliged to come in"... There were times when I walked off and cried. There's times when I've walked off and then I'd go home and do my CV again and I would apply for other jobs, but then all the other jobs that I was qualified to do were all zero hour contracts, all the time' (4).

\section{Discussion}

Overtime, ZHCs has generated intense debate, relating to dramatic increase in its use in recent years as it is associated with disproportionately negative conditions for workers. Despite the insecurity, uncertainties and its adverse effect on workers, the use of $\mathrm{ZHC}$ continue to grow. The aim of this project was to investigate the spread of ZHC to other sectors; the effect of zero hours contract on worker's health, social and family life and career wellbeing; and to compare workers experiences across sectors. The findings demonstrated that the use of ZHC in the UK has spread across many sectors including the education sector. Education is an area of the public sector that is traditionally unionised and where most employers reluctantly accept the presence of collective bargaining. The spread to the education sector echoes the growing concern about the increasing share of precarious jobs in employment [36]. Contrary to the findings by Koumenta and Williams [30] where they reported ZHC as being associated with indicators of inferior job quality characterized by low pay and underemployment, this study demonstrates that $\mathrm{ZHC}$ is also associated with highly skilled jobs such as lecturing.

Furthermore, the study demonstrates that even in this sector, the experience and impact on workers social and family life, health, career progression and job security is not different to the impact on workers from low skilled jobs. Workers like the flexible element of $\mathrm{ZHC}$ because it allows them to combine work with other responsibilities. However, the number of people who showed positive experience (6/30) were characterized by retired or semi-retired status with little or no financial burden (e.g. mortgage repayment). On the other hand, workers with financial responsibilities found it difficult working on $\mathrm{ZHC}$ because of the uncertainty as to when their services might be required and whether they will be able to earn enough to pay their bills. The study identified different ways in which ZHC can affect the worker ranging from financial insecurity, contract insecurity, impact on health and wellbeing and adverse career progression. Workers were affected differently depending on the sector in which they work.

Workers also reported having experienced health related problems such as anxiety and stress which are aspects of mental health. Although these health-related issues could not be clinically proven as caused by ZHC, the findings support research by Ravalier et al [40] done in the care sector which found out that a greater proportion of care/support workers had worse mental health issues working on ZHC than those 
who had permanent contracts. However, workers experience different levels of stress and anxiety depending on the sector they work in. While workers from the education sector (in teaching roles) were typically given fixed hours for a semester or for an academic year, workers in other roles (like, catering, cleaning, etc) had to worry almost on daily or weekly basis as to when they would get the next shift. The experience of workers in non-teaching roles in the education sector were similar to those in other sectors in terms of when work might become available. There was less possibility of work cancellation for workers in teaching roles. The yearly schedule or semester schedule for workers in the teaching role, reduced the level of stress for the workers in comparison to workers in none teaching role and other sectors. The care and hospitality sector were the most volatile as to when workers could be called to work and as to when work could be cancelled. Workers could get less than onehour notice to get to work and work could also be cancelled while they are already in the workplace with no pay.

Workers in the education sector (irrespective of their roles) had access to training even if they were not paid for the time invested in that training as opposed to workers from the care sector, who might be asked to pay for their own training. Workers in teaching role had the advantage of working on what could be described as their career path, as opposed to workers in care and hospitality where some seemed to be working in those sectors while hoping to secure a permanent job in their career pathway. The lack of support from the management and lack of appropriate/adequate training affect the worker's ability to do their work effectively which can lead to stress related outcome [6]. Wood [48] pointed out that people working on ZHC rely on the scheduling manager to get the work done to a satisfactory quality. However, the scheduling managers have been failing to support the workers to achieve this job quality through lack of training and developmental opportunities.

Workers social and family life is affected by the uncertainty of when work might become available. Workers find it difficult to plan or have to cancel social and family engagements because they were called at short notice to work. This point is in line with the study by Squires and Goldsmith (2017) who pointed out that zero hours contracts establish 'anti-social, coercive and exploitative, performance and compliance systems that detract from a sense of belonging, reinforce social divisions and exclusions, and which resemble, in all relevant respects, the wider regime of anti-social contracts impinging upon the lives of the youngest and poorest'. The study support Reilly's [42] argument that employers can use short term contracts such as zero hours contracts to deny workers employment rights and avoid liabilities. Workers in teaching role, do not have face these difficulties because their work schedule is certain and fixed for at least a semester or an academic year.

All the participants of the study (except the 6 who has very good experience of working on $\mathrm{ZHC}$ ), stated that they would like to retain the flexibility of ZHC but wanted work with guaranteed hours. Workers in hospitality, stated that most of the work in hospitality is $\mathrm{ZHC}$ and they are calling for a ban to $\mathrm{ZHC}$ to give them the opportunity to have better contracts with guaranteed hours. There have been several calls for ZHC to be banned. The Labour Party Shadow chancellor John McDonnell pledged at the Labour Party conference running up to the December 12, 2019 elections, to ban the controversial contracts "to make sure every employee has a guaranteed number of hours a week". This is a position that the Labour Party has held for several years. However, the Taylor review found banning zero-hour contracts would hurt more people than it would help [18]. The review argued that ZHC provided valued flexibility for both employers and individuals, such as carers, students, or working parents. While the flexibility offered by ZHC is helping workers balance work and other commitment, it no doubt have a negative effect on the worker. Furthermore, the way ZHC is targeted at students and mothers maybe a source of labour market and social exclusion the aim of which is to reduce labour costs. Women, students and those with lower education are over-represented among zero-hours contract workers [1].

\section{Conclusion}

The study demonstrates that the use of ZHC has spread to other sectors including the education sector. Although, workers in lecturing jobs may know their work schedule months or even a year in advance, the uncertainty, insecurity as to whether their contracts might renewed or not leaves the workers in the same vulnerable position as workers in low paid jobs. Irrespective of the flexibility that ZHC offers to the workers and the employers, workers in other sectors generally find it difficult to manage and plan because of the uncertainty as to when work might become available. All workers on ZHC including those in lecturing jobs don't fell they get the necessary training required to do their job and no hope of career progression. ZHC is associated with stress, anxiety thus affecting the wellbeing of the worker. Based on the findings presented in this paper, the following recommendations are made. 1) To provide all workers with permanent contract with an option to opt into a $\mathrm{ZHC}$ for those that want to or. 2) move $\mathrm{ZHC}$ contracts to a contract status that would guarantee some minimum works of work while retaining flexibility and improved working conditions. 3) Develop the policy on ZHC to include mandatory rights like training, workers to be given at least four weeks' notice of work and for workers to be paid where work is cancelled at very short notice. 4) Replace the use of ZHC in sectors like Education with fixed term contract.

\section{References}

[1] Adams A. and Prassl J., (2018) Zero hours work in the United Kingdom' Geneva: International Labour Office.

[2] Adams A., Freedland M. and Prassl J. (2015) The Zero Hours Contract: Regulating Casual among 25-year-olds in England. Longitudinal and Life Course Studies 10 (2): 259-276. 
[3] Adams Z and Deakin S (2014) Re-regulating zero hours contracts. Institute of Employment Rights https://www.ier.org.uk/publications/re-regulating-zero-hourscontracts accessed on the $25^{\text {th }}$ of December 2019.

[4] Autoclenz Ltd v Belcher [2011] UKSC 41

[5] Autor D. H. and Houseman S. N. (2010) Do temporary-help jobs improve labor market outcomes for low-skilled workers? Evidence from "Work First". American Economic Journal: Applied Economics 2 (3): 96-128.

[6] Bakker A. B., Demerouti E., De Boer E. and Schaufeli E. B. (2003) Job demands and job resources as predictors of absence duration and frequency. Journal of Vocational Behavior 62: 341-356.

[7] Ball M., Hampton C., Kamerade D. and Richardson H. (2017) Agency workers and zero hours - the story of hidden exploitation' Project Report. Derbyshire Unemployed Workers Centres. http://shura.shu.ac.uk/16682/ accessed $20^{\text {th }}$ December 2019.

[8] Bender K. A. and Theodossiou I. (2018) The Unintended Consequences of Flexicurity: the Health Condequences of Flexible Employment. Review of Income and Wealth 64 (4): 777-799.

[9] Booth A. L., Francesconi M. and Frank J., (2002) “Temporary Jobs: Stepping Stones or Dead Ends?” Economic Journal, 112, F189-213.

[10] Briken K. and Taylor P., (2018) 'Fulfilling the 'British way': beyond constrained choice-Amazon workers' lived experiences of workfare' Industrial Relations Journal, 49 (5-6) 438-458.

[11] Brown W., Deakin S., Nash D. and Oxenbridge S., (2000) 'The Employment Contract: from Collective Procedures to Individual Rights' British Journal of Industrial Relations, 38 (4), 611-629.

[12] Burchell J. B., (1999) 'The Unequal Distribution of Job Insecurity, 1966-86' International Review of Applied Economics, 13 (3) 437-458.

[13] Burchell, B. (2011). A temporal comparison of the effects of unemployment and job insecurity on wellbeing. Sociological Research Online, 16 (1).

[14] Burgand, S. A., Brand, J. E., and House, J. S. (2009). Perceived job insecurity and worker health in the united states. Social Science \& Medicine, 69 (5): 777-785.

[15] Cappelli P. and Neumark D., (2004) 'External churning and internal flexibility: evidence on the functional flexibility and core-periphery hypotheses' Industrial Relations, 43, 148- 182.

[16] Carmichael v National Power [2000] IRLR 43.

[17] Cunningham I. and James P., (2014) 'Public service outsourcing and its employment implications in an era of austerity: the case of British social care' Competition \& Change, 18 (1) 1-19.

[18] Department of Business Innovation and Skills, (2013) 'Consultation: Zero hours employment contracts' https://assets.publishing.service.gov.uk/government/uploads/s ystem/uploads/attachment_data/file/267634/bis-13-1275-zerohours-employment-contracts-FINAL.pdf accessed on the $25^{\text {th }}$ of December 2019.
[19] Dolado J. J., Lale E. and Turon H., (2019) 'Zero-hours Contracts in a Frictional Labor Market' Working Paper.

[20] Elliott L., (2013) 'Zero-hours contract workers - the new reserve army of labour? The Guardian, 4.8.2013.

[21] Farina, E., Green, C. P., and McVicar, D. (2020). Zero hours contracts and their growth. British Journal of Industrial Relations, 58 (3): 507-531.

[22] Filimonau V. and Corradini S., (2019) 'Zero-hour contracts and their perceived impact on job motivation of event catering staff' Event Management journal, 23, 4-5.

[23] Green, C. P. and Leeves, G. D. (2013). Job security, financial security and worker well-being: New evidence on the effects of flexible employment. Scottish Journal of Political Economy, 60 (2): 121-138.

[24] Gregg P. and J. Wadsworth, (1995) "A Short History of Labour Turnover, Job Tenure, and Job Security, 197593,"Oxford Review of Economic Policy, 11, 73-90.

[25] Henderson, M. (2019). The quarter-life crisis? Precarious labour market status and mental health.

[26] Hunter (2013) 'Banning zero hours contracts would be 'extremely damaging' In Fresh business thinking. Available at: $\mathrm{http}$ //www.freshbusinessthinking.com/banning-zero-hourscontracts-would-be-extremely-damaging/. Accessed November $30^{\text {th }}, 2019$.

[27] Jahn, E. J., Riphahn, R. T., and Schnabel, C. (2012). Flexible forms of employment: Boon and bane. The Economic Journal, 122 (562): F115-F124.

[28] Kalleberg, A. L. and Vallas, S. P. (2018). Probing precarious work: Theory, research and politics. Research in the Sociology of Work, 31: 1-30.

[29] Koumenta M. and Williams M., (2019) 'An anatomy of zerohour contracts in the UK' Industrial Relations Journal, 50 (1) 20-40.

[30] Koumenta, M. and Williams, M. (2019). 'An anatomy of zero hours contracts in theUK'. Industrial Relations Journal, 50 (1): $20-40$.

[31] Lucas, R. (1997). 'Youth, gender and part-time work students in the labour process'. Work, Employment \& Society, 11 (4): 595-614.

[32] ONS, 'People in Employment on Zero Hours Contract' (2020) Released $18^{\text {th }} \quad$ February 2020. Available https://www.ons.gov.uk/employmentandlabourmarket/peoplei nwork/employmentandemployeetypes/datasets/emp17peoplei nemploymentonzerohourscontracts.

[33] Pennycook, M., Cory, G., and Alakeson, V. (2013). A matter of time. The rise of zero-hours contracts. Report, The Resolution Foundation.

[34] Pickavance N., (2014) 'Zeroed out: The place of zerohours contracts in a fair and productive economy' April. http://www.yourbritain.org.uk/uploads/editor/files/ZHCs_r eport_final_FINAL_240414.pdf assessed 21st October 2020 .

[35] Pollert A. and Charlwood A., (2009) 'The vulnerable worker in Britain and problems at work' Work, Employment and Society, 23 (2) 343-362. 
[36] Prosser, T. (2016). 'Dualization or liberalization? Investigating precarious work in eight European countries'. Work, Employment \& Society, 30: 949-65.

[37] Pyper D. and Brown J., (2016) 'Zero Hours contracts' Briefing Paper 06553, House of Commons Library.

[38] Pyper D. and McGuinness F. (2014) 'Zero-hours contracts' Standard Note SN/BT/6553, House of Commons Library.

[39] Pyper, D. and McGuinness, F. (2018). Zero-hours contracts. Report, House of Commons Library.

[40] Ravalier J., Morton R., Russell L. and Fidalgo A., (2018) 'Zero-hour contracts and stress in UK domiciliary care workers' Health and Social Care, 27 (2), 348-355.

[41] Ravalier, J., Fidalgo, A., Morton, R., and Russel, L. (2017). The influence of zero-hours contracts on care worker wellbeing. Occupational Medicine, 67 (5): 344-349.

[42] Reilly P. (1998) 'Balancing flexibility - meeting the interests of Employer and Employee' European Journal of Work and Organisational Psychology, 7 (1), p. 7-22
[43] Rogers K., (2017) 'Precarious and migrant workers in struggle: Are new forms of trade unionism necessary in postBrexit Britain?' Capital \& Class, 41 (2), 336-343.

[44] Rubery J., Ward K., Grimshaw D. and Beynon H., (2005) 'Working time, industrial relations and the employment relationship' Time \& Society, 14 (1) 89-111.

[45] Ryan L., Lavelle J., O’Sullivan M., J. McMahon J., Murphy C., Turner T., Gunnigle P. and O'Brien M., (2019) 'Defining and Regulating Zero Hours Work: Lessons from a Liberal Market Economy' Nordic Journal of Working Life Studies, 9 (6), 75-93.

[46] Sanwald, A. and E. Theurl, "Atypical Employment and Health: A Meta-Analysis," Working Papers in Economics and Statistics, 2014-15, Faculty of Economics and Statistics, University of Innsbruck, 2015.

[47] Standing G., (2014) A precariat charter: From denizens to citizens. A\&C Black pg 73.

[48] Wood J., (2016) 'Flexibility scheduling, degradation of job quality and barriers to collective voice' Human Relations 69 (10), 1989-2010. 